\title{
Luria's Approach to the Restoration of Speech in Aphasia and the International Classification of Functioning, Disability and Health (ICFDH)
}

\author{
Maria E. Baulina ${ }^{\mathrm{a}, \mathrm{c}}$, Anatoly A. Skvortsov ${ }^{\mathrm{a}}$, \\ Maria S. Kovyazina ${ }^{a, b}$, Nataliya A. Varako ${ }^{a, b}$ \\ a Lomonosov Moscow State University, Faculty of Psychology, Moscow, Russia \\ ${ }^{\mathrm{b}}$ Research Center of Neurology, Moscow, Russia \\ ${ }^{c}$ Moscow Institute of Psychoanalysis, Moscow, Russia \\ *Corresponding author. E-mail: skwortsow@mail.ru
}

Background. Alexandria R. Luria's classic neurorehabilitation methods ("restorative learning") have now been successfully applied in clinical settings for more than seventy years. It is of interest how Luria's methods relate to contemporary strategic approaches to effective rehabilitation. One such framework is the International Classification of Functioning, Disability and Health (ICF) - a comprehensive WHO framework for measuring health and disability for diagnostic and rehabilitation purposes.

Objective. To compare Luria's procedure of restorative learning in aphasia and the ICF. Such a comparison may facilitate the use of the ICF in the work of multidisciplinary rehabilitation teams for diagnosis, planning, implementation, and evaluation of rehabilitation programs.

Design. A systematic comparison of ICF components with specific rehabilitation procedures developed by Luria aimed at speech understanding and production.

Results. Luria's speech rehabilitation methods pertain to the ICF component "Body Functions and Structures". Specific correspondences between Luria's rehabilitation procedures and ICF categories are found, especially for afferent and efferent aphasias. For the aphasias related to speech understanding (sensory and semantic aphasia), such correspondences are rare. This reflects an insufficient differentiation in the understanding of higher cognitive functions in current neurorehabilitation. Luria's concern for patients' personality and social status is also explicated.

Conclusion. Although Luria's "restorative learning" is realized within the ICF domain of "Body Functions and Structures", his approach also focuses on the rehabilitation of the personal and social status of the patient. This approach is an important condition for clinical and psychological rehabilitation in the ICF domains of "Activities" and "Participation".
Keywords:

International

Classification

of Functioning,

Disability and

Health (ICFDH),

speech, aphasia,

restorative

learning,

A.R. Luria, neuropsychology,

clinical

psychology,

rehabilitation. 


\section{Introduction}

In recent decades, there has been rapid development of research and practical rehabilitation work regarding the fundamentals of the rehabilitation process (Wilson, Winegardner, van Heugten, \& Ownsworth, 2017; Varako, Kovyazina, Zinchenko, Dobrushina, \& Ivanova, 2016). At the same time, the regulatory and legal basis for rehabilitation is changing, which is reflected in the adoption of a number of international resolutions, conventions, and corresponding definitions, and also fundamentally new classifications based on the social model of health and disabilities and characterizing a person's life activity. These place a special emphasis not on the conditions of body functions, but on the abnormalities of a person's functioning.

In this vein, the World Health Organization (WHO) developed and adopted the International Classification of Functioning, Disability and Health (ICF; 2001), which is a guideline for planning and evaluation of the effectiveness of rehabilitation measures.

Meanwhile, Russia has a unique scientific school developed by L.S. Vygotsky, A.N. Leontiev, and A.R. Luria, on the basis of which a special approach emerged to the rehabilitation of affected mental functions (called restorative learning), (Luria, 1948). It seems interesting to compare the methods of restorative learning developed by Alexander R. Luria to those developed by the ICF. This comparison may facilitate communication between specialists working in various areas of science and practice. This would reflect an important principle in ICF development: the opportunity to discuss a patient's situation with all members of the rehabilitation team in a common language (the principle of neutrality) (Builova, 2013).

The ICF can be considered an important complement to the International Classification of Diseases (ICD) (International Statistical Classification of Diseases and Related Health Problems, 2016). While the latter was created as a universal means of making a medical diagnosis, the ICF is a universal tool for describing and comparing health data. Practitioners often come across the fact that the quality of life of two patients with the same diagnosis varies significantly. One person, being wheelchair-bound, loses his job, social network, and interest in life, while the second actively participates in the life of his family, leads a support group for people with disabilities, fights for their rights, etc. Such life options for people with diseases are reflected in the ICF.

The latest edition of the ICF was published in 2001. A schematic relationship of various aspects of the health and life of the individual is shown in Figure 1. A change in health conditions according to the ICF refers to a diagnosis given to the patient according to the ICD. The disease itself is also bound to affect the condition of a person's life. Characterizing the "Body Functions and Structures" component of the ICF, it is necessary to determine which structures of the patient's organism are affected and which functions (including psychological ones) of these structures have undergone a change. The description of the extent to which certain structures and functions are used by patients in real life corresponds to the "Activities" and "Participation" components of the ICF. The condition of structures and functions, as well as the extent of their use in real-life situations, are influenced by the patients' personal traits (Personal Factors) and their social and physical environments (Environmental Factors). 


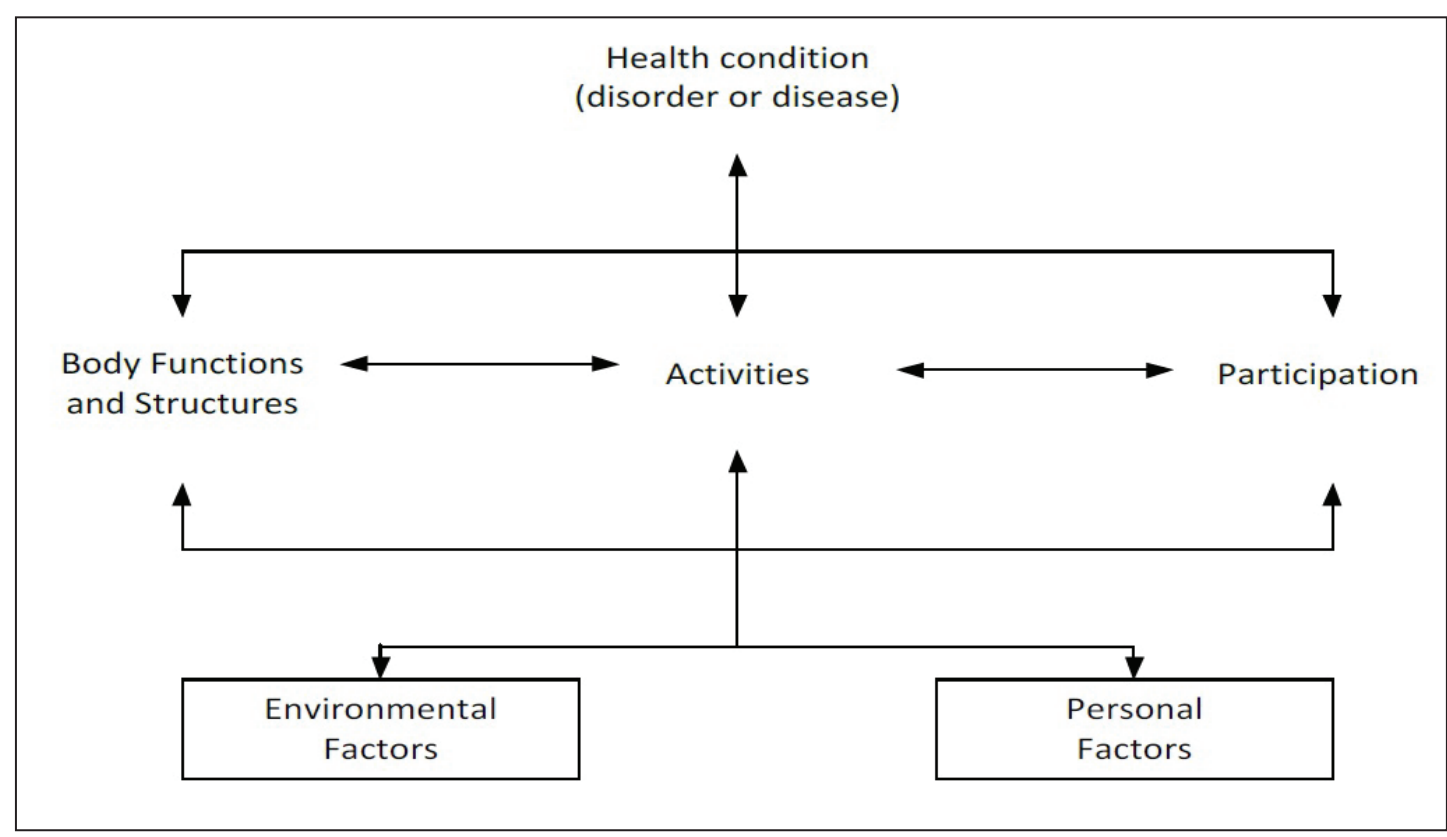

Figure 1. Interactions between the components of the ICF (International Classification of Functioning, Disability and Health, 2001).

We shall explain this scheme by using a neuropsychological example. Most experts in this field deal with patients who have suffered brain damage. Such patients may be diagnosed with "acute cerebral circulation disorder", which in the scheme described above will correspond to changes in brain function and brain structure. This diagnosis presupposes damage to various brain structures, for example, the posterior third of the superior temporal gyrus of the left hemisphere. This specification will refer to the organism structure. The primary difficulties of phonemic analysis, as well as its systemic consequences, which, as a rule, accompany damage to this structure, will characterize the functional change. Considering the "Activities/Participation" component, it is necessary to assess how much the damage to "Body Functions and Structures" influences the ability of a person to explain what he wants in a store, to maintain a dialogue with friends, to call an ambulance, etc.

This example is understood better when we consider the personal and environmental factors of the situation in which the patient lives. Personal factors may include the level of the patient's education. As a rule, the better the person is educated, the more developed is his language proficiency, which, of course, has an effect on speech processes. It can be expected that patients with higher education have a wider repertoire of speech automatisms, which to a greater extent allows them to compensate for a defect of phonemic analysis. According to Luria, patients with higher education are able to write words and whole sentences that have been reinforced by their experience "with a stroke of the pen", overcoming the phenomena of sound lability that is so characteristic of patients with sensory aphasia (Luria, 1966). In recent terminology, one could suggest that they have a higher level of available compensatory metacognitive processes (Kempler \& Goral, 2008).

The physical factors important for such patients include the presence and quality of the language environment. If a person lives alone, there is no opportunity to rely on normative sound standards of words that are present in the speech of 
healthy people. Interpersonal relationships in which the patient is involved form the social context. It is possible that even if the language environment is physically present, the patient will not make use of it if the people providing this language environment evoke antipathy in this person. Thus, the ICF is a tool that comprehensively assesses the consequences that become especially relevant for the patient.

The most important part of the complex system of rehabilitation is psychological rehabilitation, which has several components. One particularly important area is cognitive rehabilitation. In Russia, cognitive (or neuropsychological) rehabilitation as a special area of neuropsychology involved in the rehabilitation of higher mental functions (HMFs), was developed by Luria. In one of his first works, Vosstanovlenie funkcij mozga posle voennoj travmy [Restoration of brain functions after war trauma] (Luria, 1948), the author uses the terms "long-term conscious learning", "special systematic training", "restorative learning", and "making the reorganization of defective components a matter of conscious work" (pp. 71, 74, 75). In other words, this is a set of special methods aimed at reorganizing the functional system of the mind in the process of long-term training, which initially is carried out with the maximum use of consciousness and gradually leading to the automation of these techniques. The theoretical and methodological basis of Russian neuropsychological rehabilitation is the cultural-activity paradigm of L.S. Vygotsky, A.N Leontiev, and A.R Luria.

Speech, being one of the HMFs, has its own specifics, since it organizes, connects, and reconstructs other mental functions, transferring them to the category of HMFs. Speech disorders function according to the following set of general laws: "the disintegration of higher mental functions, accompanied by pathological processes, destroys in the first place the connection between symbolic and natural processes, which start to function according to primitive laws, as more or less independent psychological structures. Thus, the collapse of higher mental functions is qualitatively opposite to the process of their formation" (Vygotsky, 1984, p. 58). Luria, describing the functional collapse caused by local damage to cortical zones, noted that they "are rarely accompanied by the complete loss of any elementary function.... Even less often they lead to a complete, irreversible disintegration of the functional system as a whole. Most often, the damage to these integrative zones leads to the disintegration of a particular functional system, which now, under pathological conditions, ceases to perform the kind of afferent synthesis that it has been performing so far" (Luria, 1948, p. 58).

Aphasia syndromes, which, first of all, bring about loss of individual speech operations, are quite illustrative. Luria suggested that, in order to compensate for the functional disintegration in aphasia, it is necessary "to organize the activity in a different way ... by incorporating it into new systemic relations in order to use residual capabilities and to compensate for this defect by taking an indirect route" (Luria, 1948, p. 61). Following Vygotsky, Luria proposes, without going beyond this partially disrupted sphere, to organize its work in a different way, incorporating it in a special form of activity related to "the history of the development of this function ... (which was subsequently automated and became known as the modus operandi of this functional system)" (p. 63). In this case, compensation is due to a conscious semantic reorganization of the functional system, which takes place as the result of prolonged special training. Luria also suggested that there is another path to 
reorganizing the functional system, based on the multiple (polyreceptor) composition of the afferent field of each functional system of the brain. This is the path of intersystem rearrangement. "Certain tasks can be practically solved in completely different ways; almost any disrupted component can be replaced by another, which begins to play a corresponding new role in the reintegrated system" (p. 69). This path is also rooted in historical development and in the ontogenesis of a person's mental activity, during which the person (child) undergoes a change in operations that helps the person (child) to solve various tasks.

Such intersystem rearrangement also requires lengthy training during which the patient learns to acquire conscious control of the previously automated but now disrupted functions. After having acquired conscious control, the patient practices controlled performance of the disrupted functions until they are at least partially automated again. . "At the beginning of the training, patients become aware of their defective operations, which they have never been fully conscious of before, and start engaging new means in this process, while continuing to be aware of the techniques used. Only after quite a lengthy period (sometimes after many months) does the technique developed during training begin to become automatic, although full automation often never occurs... Functional reorganization in these cases takes place because of the conscious mastery of new methods of activity formation". Thus, restorative learning is not aimed at maintaining what remains intact in speech, but at the reintegration of a "psychological set of operations" of disturbed psychological processes (Luria, 1948, pp. 71-72). Today this would be phrased as using metacognitive resources for rehabilitation.

Special techniques for speech rehabilitation in patients with aphasia were studied by Luria's colleagues and students (e.g., Ananiev \& Astakhov, 1946; Bain, 1964; Bain et al., 1962; Chernova, 1958; Florenskaya, 1949; Kogan, 1962; Oppel, 1963; Tsvetkova, 1985; Zankova (Ed.), 1945). The treatment of any form of aphasia always relies on the intact speech components, which are further used to consciously compensate for the defect.

\section{Method}

The adoption of the ICF in the process of modern neuropsychological rehabilitation has made it necessary to develop special methods to evaluate the effectiveness of rehabilitation measures. New studies have increasingly attempted to correlate traditional approaches to diagnostics and rehabilitation of patients who have communication disorders, including aphasias and categories included in the ICF (Brandenburg et al., 2015; Grawburg et al., 2014; Simmons-Mackie, \& Kagan, 2007; Wallace et al., 2016; Wallace, Worrall, Rose, \& Le Dorze, 2017). In a survey of 24 randomized clinical trials (Xiong, Bunning, Horton, \& Hartley, 2011), all the categories found corresponded to the ICF parameters. Out of 108 studies, 53\% were connected to "organism functions", $36 \%$ to "activity and participation", and $9 \%$ to "environmental factors". The main purpose of such comparisons is the search for the most accurate means of evaluating the effectiveness of neuropsychological rehabilitation measures. The following problem has been highlighted in the literature: Most studies of patients with communication disorders are aimed at assessing the effectiveness of applied rehabilitation measures, but they don't take into con- 
sideration what contribution these measures make along with other factors (e.g., spontaneous function recovery).

The present article aims to analyze the process of recovering speech by reorganizing its functional system, as described by Luria in his early works (Luria, 1947, 1948), in the context of the ICF.

\section{Results}

Luria focuses on two aspects of speech: speech production and speech understanding. The basis of the separation of different forms of aphasia for Luria was analysis of local brain lesions and the description of neuropsychological factors that underlie the entire complex of disorders arising from localization of the lesion. Luria studied and described seven forms of aphasia: efferent motor, afferent motor, dynamic, sensory, acoustic-mnestic, semantic, and amnesic (Luria, 1947, 1948).

\section{Recovery of speech production with traumatic aphasia}

With afferent motor aphasia, the task of rehabilitation is a radical reorganization of the functional system of verbal praxis, the replacement of disintegrated kinesthetic schemes by motor schemes not based on kinesthetic afference. According to the ICF, this will fall into the category "Articulation functions. Functions of the production of speech sounds", coded as $b 320$. The therapy will include the use of less damaged elementary, involuntary, or transitive movements with the tongue or lips (spitting out tasteless food, blowing out candles, etc.). For example, to get the sound "P", the patient is given a burning match to blow out so that he focuses on the constituent components of this movement. Further, to consolidate the result obtained, the patient is offered reinforcement using unimpaired analyzer systems: showing the position of the lips to the patient during pronunciation of the sound; squeezing and releasing the patient's lips; pressing the chest; observing the proposed auxiliary schemes and images in order to understand the formation of the corresponding sounds; reliance on unimpaired writing abilities. Then, through the differentiation of the labial P sound, the labial sounds B and $\mathrm{M}$ are trained. After that, the letter is involved in the rehabilitation work, which makes it possible to generalize different variants of its sound and to differentiate sounds whose articulatory structure is similar but which still belongs to other phonemic categories. These rehabilitation procedures will make it possible to proceed to the articulation of simple words. This more advanced stage of speech production in Luria's rehabilitation method corresponds to the ICF category $b 3308$ (Fluency and rhythm of speech functions, other specified).

With efferent motor aphasia, the main goal of Luria's restorative learning is recovery of sound combinations and sequences of sounds in a word, as well as the recovery of the motor schemes of intact comprehensive speech. Given its complexity, it is unsurprising that this goal corresponds to several ICF categories: $b 3300$ "Functions of the production of smooth, uninterrupted flow of speech"; $b 3301$ "Functions of the modulated, tempo and stress patterns in speech"; $b 3308$ "Fluency and rhythm of speech functions, other specified"; $b 176$ "Specific mental functions of sequencing and coordinating complex, purposeful movements"; $b 1672$ "Mental functions that organize semantic and symbolic meaning, grammatical structure and ideas for the production of messages in spoken, written or other forms of language". 
Luria differentiated three stages of the rehabilitation work in efferent motor aphasia. In the first of them, "sound training" occurs, the goal of which is not to master typical articulation, but to transform the articulation of the "pure phoneme" into the articulation of its "positional variants", i.e., nuances that every sound of speech acquires when included in a syllable or a word (codes $b 3300,3301,3308$ ). Among the basic methods of restorative learning at the first stage is training on the internal scheme of a syllable or word, training on a number of simple sound combinations (for example, PA-AP, MA-AM), relying on auxiliary graphic schemes, tracking the sequence of sounds in similar words (for example, TAKE and KATE), putting together syllables and words out of separate letters, reliance on writing and reading, etc.

At the second stage of the restorative learning, rehabilitation procedures are aimed at the analysis of morphological and semantic aspects of a word (b 1672). This is important, as the unity of sound and meaning in the acute period of brain damage is disrupted and sound combinations lose their meaning. Acquiring the skill of word root isolation and the formation of a word family from this root makes it possible to expand the diapason of speech production used by the patient.

At the third stage of rehabilitation in efferent motor aphasia, the goal is recovery of the grammatical aspects of an utterance $(b$ 1672). This stage is necessary because while the nominative function of a word may be preserved, its predicative aspect might be lost in efferent motor aphasia. During this rehabilitation stage, the patient is given tasks containing two-word utterances. To realize that the utterance should always have a predicate, the patient is asked to view pictures and describe the actions depicted in them, to fill in omissions in the text with the appropriate predicates, and to work on the grammatical change of the word in the utterance.

\section{Recovery of speech understanding with traumatic aphasia}

The rehabilitation of a patient with sensory aphasia starts with restoring the correct sound analysis of the word and obtaining stable and generalized sound (phonemic) groups. This corresponds to the ICF code $b 16700$ (Mental functions of decoding spoken messages to obtain their meaning). To this end, the patient is advised to rely on the meaning of the word. For example, a patient analyzes a series of words that sound similar (for example, GAME and CAME). Writing helps, too, since working on letters ("graphemes") allows the patient to understand the generalized symbols of the sounds, to isolate individual sounds in the complex composition of the sounds of a word, to become aware of the presence of vowels, and to decompose the complex sets of consonants. Kinesthetic and optical support are provided by palpation of the larynx, observation of differences in the exhaled air, use of object images with descriptions, etc.

At the next stage, Luria suggested restoring the semantic aspect of speech. These rehabilitation procedures are based on methods that help to establish the constant meaning of the stem of a word. This task is realized with the help of exercises aimed at giving semantic consistency to words that have changing forms. Tasks offered to patients are associated with inclusion of words in fixed phrase constructions with a constant meaning, for clarifying the semantic aspects of the word. Afterwards, the meanings of the same word are mastered in several semantic contexts with different phraseological contexts. Special attention is given to the suffixes and inflexions of the word. 
Overcoming semantic aphasia involves the recovery of understanding of grammatical relationships within spoken utterances. Although this is certainly a complex set of cognitive abilities, the only ICF code that seems to correspond to it is still $b 16700$ (Mental functions of decoding spoken messages to obtain their meaning). The general approach of restorative learning for semantic aphasia consists of replacing the immediate "observation of relations" by the patient, using surface features like word proximity within an utterance, with consistent reasoning based on a number of external auxiliary aids. Among the techniques developed by Luria, the most important is mastery of grammatical constructions that express semantic relations between entities. This can be demonstrated by a classic example of patients learning to differentiate the meanings of the utterances "The sun is eclipsed by the moon" vs. "The moon is eclipsed by the sun". Other techniques include reliance on inflections and awareness of the form of the main word and the addition of a demonstrative pronoun serving as an external orienting sign and playing the role of an indicating gesture, deixis ("The brother of this father"). At the final stage of Luria's restorative learning of patients with semantic aphasia, the patient gets a grasp of the semantics of prepositional constructions based on pictorial schemes (under / below, over / above, etc.).

On a general note, there is a striking difference in the correspondence between speech functions targeted by Luria's rehabilitation methods and the ICF categories. For speech production aphasias, there is an abundance of correspondence. This may reflect the obvious fact that dysfunctions in motor and sensory areas are very well described by contemporary neuroscience and medicine, so that detailed links between Luria's rehabilitation procedures and the ICF codes can be established. This close correspondence allows one to see, for example, that Luria's rehabilitation methods developed in the 1940s reflect the idea, now widely accepted, of a vertical organization of cognition (Challis \& Velichkovsky, 1999). Luria's rehabilitation methods for efferent motor aphasia, for example, gradually progress through mastering the most basic (data-driven, bottom-up) aspects of sound production, to mastering much more abstract (conceptually driven, top-down) speech production rules. However, for aphasias related to speech understanding, only one correspondence with the ICF categories could be found. This is despite the fact that Luria's rehabilitation methods are very well developed also in this respect. The lack of differentiation of functions related to speech understanding in the ICF surely reflects a lack of full understanding in contemporary neuroscience and medicine of higher order cognitive functions related to conceptual/semantic processing. In this respect, Luria's system of rehabilitation procedures may serve as a conceptual and empirical basis for future research in this area.

\section{Luria's aphasia rehabilitation and other ICF components}

Comparison of the process of Luria's speech rehabilitation procedures in different forms of aphasia with the components of the ICF showed that the main work carried out by a neuropsychologist in Russia is carried out within the domain of the ICF "Body Functions and Structures". Even within this domain, Luria advanced the use of the holistic syndrome approach in the rehabilitation of patients with local brain lesions. These rehabilitation methods are focused on the patient's spe- 
cific mental processes, many of them of a metacognitive nature. Within this syndrome approach, rehabilitation exploits syndrome-forming mechanisms. While Luria's rehabilitation procedures seem to set aside the properties and structure of the personality (Luria, 1966), Luria's rehabilitation methods are always applied in the context of patients' activities, spontaneous behaviors, and social relations. For instance, special attention is given in Russian neuropsychology to patients with an objectively high recovery potential, who, however, lack the motivation to work with a neuropsychologist, or to patients who are fundamentally unable to restore impaired functions at the level of restructuring the brain's functional systems, due to depression and impaired consciousness. Luria understood these limitations very well and stated them explicitly: "This possibility is due to the fact that the functional systems of the brain are based on the interaction of many areas. In cases where the brain injury leaves unaffected the apparatuses directly connected with the retention of stable motives and does not lead to an anatomical inability to create new functional relations between individual regions of the brain, the patient will always have a way to compensate for the defect by adjustment of functional systems “ (Luria, 1948, p. 774). Thus, Luria never forgot about the patients' functioning, their activities, and always showed an interest in specific individual behavior. This is shown in his famous case studies illustrating the ideas of "romantic medicine", such as The Mind of a Mnemonist (Luria, 1968) and The Man with a Shattered World (Luria, 1972). Such an approach corresponds very well with the introduction of the Activities/Participation components into the ICF.

\section{Conclusion}

In the modern approach to the rehabilitation of patients with aphasia, the ICF makes it possible to design and evaluate the process of cognitive rehabilitation at psychologically different levels: from the physiological support of cognitive processes, to the level of individual social relations. We have explicated how elements of the classic approach to the neurorehabilitation of aphasias developed by A.R. Luria in the 1940s are related to the ICF categories. We have shown that Luria's methods of rehabilitation of speech production fit well with the ICF categories, and that Luria's methods of rehabilitation of speech understanding still seem to be much more differentiated than the classifications proposed by the ICF. We have also tried to show that while Luria's rehabilitation procedures are more within the ICF "Body Functions and Structures" domain, in Luria's neuropsychology there was always a special consideration of patients' activities, personalities, and environments. This is in close correspondence with the contemporary philosophy behind the ICF. Thus, restorative learning based on Luria's theory of systemicdynamic localization of higher mental functions takes its rightful place in rehabilitation of patients with brain lesions and in the complex interrelated structure of ICF domains.

\section{Acknowledgments}

This study was funded by the Russian Foundation for Basic Research, project No. 17-29-02169. 


\section{References}

Ananiev, B.G., \& Astakhov, S.N. (1946). Kliniko-psihologicheskij analiz vosstanovleniya rechevyh funkcij pri motornoj afazii [Clinical and psychological analysis of the restoration of speech functions in motor aphasia]. In S.N. Davidenkov \& I.S. Weinberg, Voprosy obshchej i klinicheskoj nevropatologii (trudy nevropatologov Leningrada). [Problems of general and clinical neuropathology (works of the neuropathologists of Leningrad), in 3 vols. (pp. 227-236). Leningrad: Gosudarstvennyj Ordena Lenina Institut usovershenstvovaniya vrachej im. S.M. Kirova.

Bain, E.S. (1964). Afaziya i puti ee preodoleniya [Aphasia and ways to overcome it]. Leningrad: Medicine.

Bain, E.S., Gertsenstein, E.N., Rudenko, Z.Y., Taptapova, S.L., Chernova, A.D., \& Shokhor-Trotskaya, M.K. (1962). Posobie po vosstanovleniyu rechi u bolnyh s afaziej [Manual for speech restoration in patients with aphasia]. Moscow: Medgiz.

Brandenburg, C., Worrall, L., Rodriguez, A., \& Bagraith, K. (2015). Crosswalk of participation self-report measures for aphasia to the ICF: What content is being measured? Disability and Rehabilitation, 37(13), 1113-1124. https://doi.org/10.3109/09638288.2014.955132

Builova, T.V. (2013). Mezhdunarodnaya klassifikaciya funkcionirovaniya kak klyuch k ponimaniyu filosofii reabilitacii [International classification of functioning as a key to understanding the philosophy of rehabilitation]. Medial, 2(7), 26-31.

Challis, B.H., \& Velichkovsky, B.M. (Eds.) (1999). Stratification in cognition and consciousness. Amsterdam: John Benjamins Publishing. https://doi.org/10.1075/aicr.15

Chernova, A.D. (1958). Vosstanovlenie rechi pri zabolevaniyah golovnogo mozga [Rehabilitation of speech in diseases of the brain]. Moscow: Medgiz.

Florenskaya, Yu.A. (1949). Klinika i terapiya narushenij rechi [Clinical picture and therapy of speech disorders]. Moscow: Medgiz.

Grawburg, M., Howe, T., Worrall, L., \& Scarinci, N. (2014). Describing the impact of aphasia on close family members using the ICF framework. Disability and Rehabilitation, 36(14), 1184-1195. https://doi.org/10.3109/09638288.2013.834984

International Classification of Functioning, Disability and Health (ICFDH). (2001). Geneva: World Health Organization.

International Statistical Classification of Diseases and Related Health Problems (10th revision, 5th edition). (2016). Geneva: World Health Organization.

Kempler, D., Goral, M. (2008). Language and dementia: Neuropsychological aspects. Annual Review of Applied Linguistics, 28, 73-90. https://doi.org/10.1017/S0267190508080045

Kogan, V.M. (1962). Vosstanovlenie rechi pri afazii [Recovery of speech in aphasia]. Moscow: TsIETIN.

Luria, A.R. (1947). Travmaticheskaya afaziya: klinika, semiotika $i$ vosstanovitelnaya terapiya [Traumatic aphasia: clinical picture, semiotics and restorative therapy]. Moscow: Publishing House of the Academy of Medical Sciences of the USSR.

Luria, A.R. (1948). Vosstanovlenie funkcij mozga posle voennoj travmy [Restoration of brain functions after war trauma]. Moscow: Publishing House of the Academy of Medical Sciences of the USSR.

Luria, A.R. (1966). Higher cortical functions in man. New York, NY: Basic Books.

Luria, A.R. (1968). The mind of a mnemonist: A little book about a vast memory. Cambridge, Mass., and London: Harvard University Press.

Luria, A.R. (1972). The man with a shattered world: The history of a brain wound. Cambridge, Mass.: Harvard University Press. 
Oppel, V.V. (1963). Vosstanovlenie rechi pri afazii (Metodicheskie ukazaniya) [Speech restoration in aphasia (Methodical instructions)]. Leningrad: Medgiz.

Simmons-Mackie, N., \& Kagan, A. (2007). Application of the ICF in aphasia. Seminars in Speech and Language, 28(4), 244-253. https://doi.org/10.1055/s-2007-986521

Tsvetkova, L.S. (1985). Nejropsihologicheskaya reabilitaciya bol'nyh. Rech' i intellektual'naya deyatel'nost' [Neuropsychological rehabilitation of patients. Speech and intellectual activity]. Moscow: Moscow University Press.

Varako, N.A., Kovyazina, M.S., Zinchenko, Y.P., Dobrushina, O.R., \& Ivanova, G.E. (2016). East and West tradition in neuropsychological rehabilitation: Building bridges. Journal of the International Neuropsychological Society, 22(S2). https://doi.org/10.1017/S1355617717000030

Vygotsky, L. S. (1984). Sobranie sochinenij: V 6-ti tomakh. T. 6. Nauchnoe nasledstvo [Collected works: In 6 volumes. Vol. 6. Scientific heritage]. Moscow: Pedagogika.

Wallace, S.J., Worrall, L., Rose, T., \& Le Dorze, G. (2017). Using the International Classification of Functioning, Disability, and Health to identify outcome domains for a core outcome set for aphasia: A comparison of stakeholder perspectives. Disability and Rehabilitation, 1-10. https://doi.org/10.1080/09638288.2017.1400593

Wallace, S.J., Worrall, L., Rose, T., Le Dorze, G., Cruice, M., Isaksen, J., Kong, A.Ph. ... Gauvreau, C.A. (2016). Which outcomes are most important to people with aphasia and their families? An international nominal group technique study framed within the ICF. Disability and Rehabilitation, 39(14), 1-16. https://doi.org/10.1080/09638288.2016.1194899

Wilson, B.A., Winegardner, J., van Heugten, C.M., \& Ownsworth, T. (Eds.) (2017). Neuropsychological rehabilitation: The international handbook. London, New York: Routledge, Taylor \& Francis Group. https://doi.org/10.4324/9781315629537

Xiong, T., Bunning, K., Horton, S., \& Hartley, S. (2011). Assessing and comparing the outcome measures for the rehabilitation of adults with communication disorders in randomised controlled trials: An International Classification of Functioning, Disability and Health approach. Disability and Rehabilitation, 33(23-24), 2272-2290. https://doi.org/10.3109/0963 8288.2011.568666

Zankova, L.V. (Ed.) (1945). Psihologo-pedagogicheskie problemy vosstanovleniya rechi pri cherepno-mozgovyh raneniyah: trudy Nauchno-issledovatel'skogo instituta defektologii Akademii pedagogicheskih nauk RSFSR, Otdelenie psihologii. [Psychological and pedagogical problems of speech restoration in craniocerebral wounds: Works of the Research Institute of Defectology of the Academy of Pedagogical Sciences of the RSFSR, Department of Psychology]. Izvestiya Akademii pedagogicheskih nauk RSFSR, Vypusk 2. [News of the Academy of Pedagogical Sciences of the RSFSR]. Issue 2: Moscow: Izd-vo Akad. ped. nauk RSFSR.

Original manuscript received December 07, 2018

Revised manuscript accepted January 10, 2019

First published online February 15, 2019

To cite this article: Baulina, M.E., Skvortsov, A.A., Kovyazina M.S., Varako, N.A. (2019). Luria’s approach to the restoration of speech in aphasia and the International Classification of Functioning, Disability and Health (ICFDH). Psychology in Russia: State of the Art, 12(1), 118-128. DOI: 10.11621/pir.2019.0109 